\title{
Inhalt des Jahrgangs 2003
}

BOGEN, ANDREY, Über ein Gedicht von Boris Pasternak

Danielewiczowa, Magdalena; Zielińska, AnNa, Mentale Verben in der Polszczyzna północnokresowa: Ein Klassifikationsversuch

FIALA, EDWARD, Der existentielle Gombrowicz

GRAF, AlEXANDER, Die Bedeutung Puškins für den zeitgenössischen Manierismus

HINZE, FRIEDHELM, Zur Bezeugung und Etymologie des pommerschen Familiennamens Krofey Zugleich Bemerkungen zu Leben und Hauptwerk des Simon Krofey

HODEL, ROBERT, Zum Epochenübergang vom Realismus in die Moderne: Korrelation von Metrisierung und Syntax bei Tolstoj und Belyj

Holvoet, AXEL, Modal constructions with 'be' and the infinitive in Slavonic and Baltic

KEUTEN, Alla, Unbekannte Herder- und Geßner-Übersetzungen aus dem Archiv Deržavins

RadünZEl, Claudia, Die Reden Präsident Putins und Bundeskanzler Schröders auf dem Milleniumsgipfel der Vereinten Nationen: Eine kontrastive Analyse

RYTEL-KuC, DANUTA, Phraseologische Wortpaare in der polnischen Gegenwartssprache im Vergleich zum Tschechischen und Deutschen

SCHMIDT, HENRIKE, Knoten im Netz: Literaturwettbewerbe im russischen Internet

SoBoleva, MaJA, Nikolaj Fedorovs „Philosophie der gemeinsamen Tat“ im Lichte der modernen Bioethikdiskussion

WIEMER, BJÖRN, Grammatische Kategorien und Grammatikalisierung in der Forschung der Sowjetunion und Polens: Beitrag zu einem bislang nicht aufgearbeiteten wissenschaftsgeschichtlichen Kapitel

WINGENDER, MONIKA, Das Wortfeld der Quantität im Polnischen

Beiträge zum XIII. Internationalen Slavistenkongress in Ljubljana (15. - 21. August 2003)

ECKERT, RAINER, Nominalisierungstendenzen im Slawischen und Baltischen (Nomen actionis anstelle des Verbum finitum)

GiEsEmanN, GERHARD, Die barocke Komponente und ihre Varianten in der Lyrik France Prešerens

JEKUTSCH, UlRIKE, Zur Konzeption des ,Südens' bei Nikolaj A. Zabolockij

KEIPERT, HELMUT, J. W. Paus und die russische Grammatikographie vor Lomonosov

Kosta, PETER, Syntaktische und semantische Besonderheiten von Negation und Adverb im Slavischen (unter besonderer Berücksichtigung des Russischen, Tschechischen und Südslavischen)

Krause, Marion; Ljublinskaja, Valentina u. a., Mentale Dialektkarten und Dialektimages in Russland: Metasprachliches Wissen und Bewertung von Dialekten

KunZmanN-Müller, BARBARA, Schnittstelle Grammatik-Lexikon am Beispiel nicht persönlicher Konstruktionen im Slavischen

KUBE, HOLGER, Mentale Verben als argumentative Prädikate: Invarianten und Verwendungen am Beispiel der „Dialektika mifa“ Aleksej Losevs

MENGEL, SVETLANA, Übersetzungsprojekte hallischer Pietisten zu Beginn des 18. Jhs. auf dem Hintergrund der sprachpolitischen Diskussion um die neuere russische Literatursprache

MEYER-FrAATZ, ANDREA, Literarisierte Emotionalität in den Sonettzyklen von Adam Mickiewicz und France Prešeren 
SCHALleR, Helmut W., Das Slowenische und seine Bedeutung für die vergleichende Betrachtung der slawischen Sprachen

SCHMÜCKER-BRELOER, MARITTA, „Skazanie o dvenadcati pjatnicach“: Zur Distribution und Rezeption eines apokryphen Textes

UdOLPH, LUDGER, Die Konfessionalisierung der Lausitzen und die sorbischen Bibelübersetzungen (16. - 18. Jahrhundert)

Voss, Christian, Verschriftungsversuche des Ägäis-Makedonischen im 20. Jahrhundert

WIEMER, BJÖRN, Zur Verbindung dialektologischer, soziolinguistischer und typologischer Methoden in der Sprachkontaktforschung: Das Beispiel slavischer und litauischer Varietäten in Nordostpolen, Litauen und Weißrussland

\section{Tagungsbericht}

Zhdanova, Vladislava, 12. Fachtagung Slawistik der Deutschen Gesellschaft für Osteuropakunde: „Kulturelle Konstanten Russlands im Wandel“"

\section{Nekrolog}

ECKERT, RAINER, In memoriam Akademiemitglied Oleg Nikolaevið Trubačev

\section{Buchbesprechungen}

KASACK, WolfGang, Christus in der russischen Literatur: Ein Gang durch die Literaturgeschichte von ihren Anfängen bis zum Ende des 20. Jahrhunderts - besprochen von Norbert Franz

KRYLOV, IVAN ANDREEVIČ, Polnoe sobranie dramatičeskich sočinenij; PLAVIL'ščIKOV, PETR ALEKSEEVIČ, Sobranie dramatičeskich sočinenij besprochen von Witold Kośny

Leonid Leonov $\mathrm{i}$ russkaja literatura $\mathrm{XX}$. veka: Materialy jubilejnoj naučnoj konferencii, hrsg. von V. P. MUROMSKIJ und T. M. VACHITOVA - besprochen von Uta Scholz

SaleVSKY, HEIDEMARIE, Translationswissenschaft: Ein Kompendium. Bd. 1. Unter Mitarbeit von Ina Müller und Bernd Salevsky - besprochen von Wladimir Bykow

SCHMID, ULRICH, Russische Religionsphilosophen des 20. Jahrhunderts - besprochen von Dirk Uffelmann

Socrealisticeskij kanon. Pod obšcej red. CH. GJUNTERA i E. DOBRENKo - besprochen von Andreas Guski

WACH, MARGARETE, Krzysztof Kieślowski: Kino der moralischen Unruhe; ŽlžEK, SlavoJ, Die Furcht vor echten Tränen: Krzysztof Kieślowski und die „Nahtstelle" - besprochen von Ulrike Katja Seiler 